\title{
AVALIAÇÃO DAS QUALIDADES FORRAGEIRAS DA JITIRANA (Merremia Aegyptia) E SEU POTENCIAL USO NA ALIMENTAÇÃO ANIMAL
}

\author{
Paulo César Ferreira Linhares \\ Eng. Agrônomo Mestrando em Agronomia: Fitotecnia - UFERSA, Caixa Postal 137, 59625-900 Mossoró-RN \\ Adalberto Hipólito de Sousa \\ Eng. Agr. M. Sc. Doutorando em Entomologia Universidade Federal de Viçosa. E-mail: \\ adalberto@insecta.ufv.br \\ José Flaviano Barbosa de Lira \\ Eng. Agr. Coopervida, rua Machado de Assis, 125 - Centro \\ Mossoró - RN. E-mail: jflaviano@terra.com.br
}

\begin{abstract}
RESUMO - O objetivo do trabalho foi avaliar as características químico-bromatológica da jitirana, bem como seu potencial na alimentação animal. A Jitirana foi ceifada com 115 dias para avaliação da produção de massa verde e análise químico-bromotológica. As amostras foram retiradas de uma área experimental de 35 x $35 \mathrm{~m}$, fazendo-se assim $1.050 \mathrm{~m}^{2}$. As amostras foram levadas para o laboratório de nutrição animal do Departamento de Zootecnia (DZ / ESAM), para serem feitas as devidas análises de matéria seca, proteína bruta, extrato etéreo, resíduo mineral, material orgânica e energia bruta. Apesar do baixo percentual de matéria seca da forragem verde da jitirana, os percentuais de proteína bruta, resíduo mineral e extrato etéreo, além da produção de massa verde foram satisfatórios.
\end{abstract}

Palavras-chave: Merremia aegyptia, análise químico-bromotológica, forrageira

\begin{abstract}
The objective of the work went evaluate the characteristic chemicalbromatológica of the jitirana, as well as its potential in the animal feeding. Jitirana was harvested with 115 days for evaluation of the production of green mass and analysis chemical-bromotológica. The samples were removed of an experimental area of $35 \times 35 \mathrm{~m}$, being made like this $1.050 \mathrm{~m} 2$. The samples were taken for the laboratory of animal nutrition of the Department of Zootecnia (DZ / ESAM), for they be made the due matter analyses it evaporates, gross protein, ethereal extract, mineral residue, organic material and gross energy. In spite of the percentile bass of dry matter of the green forage of the jitirana, the percentile of gross protein, mineral residue and ethereal extract, besides the production of green mass were satisfactory.
\end{abstract}

Key words: Merremia aegyptia, analysis chemical-bromotológica, forrageira 


\section{REVISTA VERDE DE AGROECOLOGIA E DESENVOLVIMENTO SUSTENTÁVEL GRUPO VERDE DE AGRICULTURA ALTERNATIVA (GVAA)}

\section{INTRODUÇÃO}

O estudo de alternativas, para alimentar os animais durante o período seco do ano, se faz necessário conhecer as espécies forrageiras nativas da região que poderão possivelmente, serem aproveitadas para a prática da fenação, da ensilagem e serem utilizadas na alimentação de animais durante período seco e de escassez de forragem.

A produtividade dos rebanhos, nas regiões secas, é muito baixa, destacando-se como fatores determinantes nos sistemas de criação, a baixa disponibilidade qualitativa e quantitativa das forragens durante os períodos de estiagens. Enquanto uma pastagem de buffel (Cenchurs Ciliaris L.) pode apresentar uma disponibilidade de $6 \mathrm{t}$ /ha de matéria seca, uma Caatinga bruta 0,9 t/ha, que têm de ser consumido ainda durante a estação chuvosa. (ALBUQUERQUE, 1988; ARAÚJO, 1987).

A devastação da vegetação nativa contribuiu não só para o desaparecimento de espécies lenhosas forrageiras, mas também para iniciar a sucessão de muitas espécies da Caatinga e até a extinção de plantas do extrato herbáceo indispensável, para a alimentação animal, onde se encontravam espécies forrageiras de bom valor nutritivo como: Oró (Phaseolus panduratus), Cunhã (Centrosema angustifolium Benth), feijão de porco (Carnavalia ensiformis), feijão de boi (Cappares flexuosa L) e a Jitirana (Merremia aegyptia) pertence à família das convolvuláceas, ainda muito abundante, na região Semi-Árida do nordeste brasileiro, considerada como invasora de pastagens e das lavouras cultivadas (CORREIRA, 1984).

Durante o período de estiagem a situação torna-se mais crítica, para a criação dos rebanhos. O estrato herbáceo seca e desaparece, a disponibilidade de forragem, para os animais, às folhas das árvores que compõem a vegetação lenhosa, secam e cai ao chão elevando o grau de intensidade do problema relacionado com a diminuição drástica da carga animal e a extensão do período de seco do ano. Parece, lógico que a redução da carga animal, possa diminuir os efeitos causados pelo superpastoreiro, entretanto, a sua aplicação não é tão simples como parece. Uma alternativa razoável seria a exploração da Caatinga no seu estado natural, dando-se um manejo visando o aproveitamento racional das espécies desejáveis. (NOVELY, 1982).

Deve ser considerado que, durante a estação das chuvas, a produção de fitomassa do estrato herbáceo, apesar de ocorrer num período curto, dois a quatro meses do ano excede a capacidade de consumo dos rebanhos, permitindo a seleção de determinadas espécies pelos animais, resultando em perdas de forragem. Por outro lado, grande parte da massa verde produzida nos estratos arbustivosarbóreo só estará disponível aos animais, sob forma de feno, natural, conseqüentemente com menor valor nutritivo, que se intensificará com a queda das folhas, decorrente do período de estiagem (ARAÚJO, 1990).

As composições químicas de várias forrageiras nativas, como o mororó Bauhinia cheilantha, (Bong Itend), o juazeiro (Zyziphus juazeiro, Mart), o sabiá (mimosa caesalpinifolia, Benth), a camaratuba (Cratylia mollis, Mart), o molegue duro (cordia leucocephala), a maniçoba (Manihot psedoglassiovil, Pax e Hoff), a orelha de onça (Macroptiluem martii, Benth), entre outras foram estudadas por (ARAÚJO, 1987); (GOMES, 1977; SALVIANO, 1984).

A jitirana (Merremia aegyptia) é uma forrageira nativa da região Semi-Árida brasileira, suculenta e com odor agradável, que confere uma ótima aceitação pelos animais, principalmente caprinos, ovinos e bovinos em sistema de pastejo, fazendo parte de sua dieta sempre que é encontrada na pastagem. Sendo a jitirana encontrada nas matas, cercas, clareiras, roçados e em diferentes tipos de solos: arenosos, argiloso, arenoso-argiloso e massapé (CORREIA, 1984). 


\section{REVISTA VERDE DE AGROECOLOGIA E DESENVOLVIMENTO SUSTENTÁVEL GRUPO VERDE DE AGRICULTURA ALTERNATIVA (GVAA)}

Este trabalho foi realizado com o objetivo de avaliar as características químicobromatológica da jitirana, contribuindo, dessa maneira, para ampliar os conhecimentos das

\section{MATERIAL E MÉTODOS}

O experimento foi conduzido no campus da Escola Superior de Agricultura de Mossoró ESAM/RN, visando avaliar as qualidades forrageiras da jitirana (Merremia aegyptia) na alimentação animal, na forma de feno, silagem ou em forma direta na utilização de pastejo.

A região de Mossoró de acordo com Amorim \& Carmo Filho (1981) apresenta precipitação anual em torno de $67 \mathrm{~mm}$, com temperatura média de $27,40^{\circ} \mathrm{C}$, latitude sul $5^{\circ}$ 11'; longitude oeste $37^{\circ} 20^{\prime}$; umidade relativa do ar $68,90 \%$; velocidade do vento $4,10 \mathrm{~m} / \mathrm{s}$; altitude ao nível do mar $18 \mathrm{~m}$; com ventos predominantes no sentido Nordeste; pressão atmosférica 757,30 mmHg; insolação 236h/mês; evaporação a sombra 5,75 mm/dia e evaporação a céu aberto $7,70 \mathrm{~mm} /$ dia.

A jitirana foi ceifada com lâmina cortante, aos 115 dias de uma área experimental do campus da ESAM, com $1.050 \mathrm{~m}^{2}$, em solo areno-argiloso. Foram retiradas 20 amostras de uma área conhecida de $1 \mathrm{~m}^{2}$, aleatoriamente, para a determinação da produção de massa verde e composição químico-bromatológica. Após o corte, o material verde foi pesado no campo e levado para o laboratório de nutrição animal do Departamento de Zootecnia da ESAM (DZ/ESAM). Foi colocado na estufa de circulação de ar por 48 horas à $65^{\circ} \mathrm{C}$, para a pré-secagem e posterior análise dos parâmetros qualidades forrageiras da jitirana, e o seu potencial no uso da alimentação animal., bem como seu potencial na alimentação animal

a serem estudados: Matéria Seca (MS), Matéria Orgânica (MO), Resíduo Mineral (RM), Proteína Bruta (PB), Extrato Etéreo (EE) e Energia Bruta (EB), seguindo a metodologia descrita por Silva (1990).

Adotou-se as recomendações de Harris (1970) e Fraga et. al. (1984), para coleta de amostra do material em estudo, sendo procedida de forma mais representativa possível.

As amostras da forragem verde, após présecagem em estufa, com circulação de ar forçada a uma temperatura de $55^{\circ} \mathrm{C}$ por 72 horas, foram trituradas em moinho do tipo Wiley dotado de peneira de 20 "mesh" e em seguida, acondicionadas em sacos plásticos de polietileno para as análises subseqüentes.

A matéria seca foi obtida mediante secagem em estufa a $105^{\circ} \mathrm{C}$ de acordo com Lenkeit \& Becker (1956).

Para obtenção da matéria mineral das amostras, utilizou-se o método de incineração simples em mufla a $600^{\circ} \mathrm{C}$, segundo descrito por Harris (1970). O conteúdo da matéria orgânica (MO) foi calculado por diferença de 100.

Seguiu-se o método micro-kjeldahl para a determinação do teor de nitrogênio $(\mathrm{N})$, extrato etéreo e a energia bruta em calorímetro adiabático, tipo PARR, das silagens, conforme método descrito por Silva (1990).

da Jitirana (Merremia aegyptia), com 115 dias de idade, além da produção de massa verde na referida idade (Tabela 2). A literatura não

Na Tabela 1, estão apresentados os resultados da análise químico-bromatológica 


\section{REVISTA VERDE DE AGROECOLOGIA E DESENVOLVIMENTO SUSTENTÁVEL GRUPO VERDE DE AGRICULTURA ALTERNATIVA (GVAA)}

dispõe de dados de composição dessa espécie vegetal.

TABELA 1: Composição químico-bromatológica da forragem verde de jitirana (Merremia aegyptia) com base na $\mathrm{MS}\left(105^{\circ} \mathrm{C}\right)$

\begin{tabular}{|c|c|c|c|c|c|c|}
\hline Componentes Químicos & $\begin{array}{c}\text { MS } \\
\mathbf{( \% )}\end{array}$ & $\begin{array}{c}\text { MO } \\
\mathbf{( \% )}\end{array}$ & $\begin{array}{c}\text { PB } \\
\mathbf{( \% )}\end{array}$ & $\begin{array}{c}\text { RM } \\
\mathbf{( \% )}\end{array}$ & $\begin{array}{c}\text { EE } \\
\mathbf{( \% )}\end{array}$ & $\begin{array}{c}\text { ENERGIA } \\
\text { (Kcal) }\end{array}$ \\
\hline Média & 11,5 & 92,14 & 14,86 & 7,86 & 2,02 & 3,500 \\
\hline
\end{tabular}

TABELA 2: Dados obtidos de 20 amostras de massa verde de jitirana (Merremia aegyptia), de uma área de $1.050 \mathrm{~m}^{2}$.

\begin{tabular}{|l|c|c|c|c|c|c|c|c|c|c|}
\hline & $\mathbf{1}$ & $\mathbf{2}$ & $\mathbf{3}$ & $\mathbf{4}$ & $\mathbf{5}$ & $\mathbf{6}$ & $\mathbf{7}$ & $\mathbf{8}$ & $\mathbf{9}$ & $\mathbf{1 0}$ \\
\cline { 2 - 12 } & 2,3 & 2,2 & 2,2 & 2,4 & 2,1 & 2,0 & 2,3 & 2,0 & 2,5 & 2,3 \\
\cline { 2 - 12 } & $\mathbf{1 1}$ & $\mathbf{1 2}$ & $\mathbf{1 3}$ & $\mathbf{1 4}$ & $\mathbf{1 5}$ & $\mathbf{1 6}$ & $\mathbf{1 7}$ & $\mathbf{1 8}$ & $\mathbf{1 9}$ & $\mathbf{2 0}$ \\
\cline { 2 - 11 } & 2,1 & 2,3 & 2,5 & 2,0 & 2,0 & 2,1 & 2,2 & 2,3 & 2,4 & 2,0 \\
\hline
\end{tabular}

Média: $2,21 \mathrm{~kg} / \mathrm{m}^{2}$. Estimativa P/ha: $22.100 \mathrm{~kg} / \mathrm{ha}$

O teor de proteína bruta encontrado na massa verde da Jitirana $(14,86 \%)$, foi superior ao feno de orelha de onça $(7,94 \%)$, camaratuba $(10,8 \%)$, jitirana $(7,63 \%)$ e marmeleiro (11,63\%), citado respectivamente por Oliveira (1988); Vale (1983); Araújo (1996) e Araújo (1990). O mesmo foi inferior ao feno de mororó (14,93\%) citado por Araújo (1996).

O resíduo mineral obtido para a forragem verde de Jitirana foi de 7,86\%, sendo superior ao feno de jitirana, citado por Araújo (1996) e inferior ao feno de marmeleiro e feijão bravo, citado por Araújo (1996).

\section{CONCLUSÃO}

Apesar do baixo percentual de matéria seca da forragem verde da jitirana, os percentuais de proteína bruta, resíduo mineral e extrato etéreo, além da produção de massa verde que credenciam este espécie vegetal como uma boa forrageira.

\section{REFERÊNCIAS BIBLIOGRÁFICAS}

O extrato etéreo obtido na forragem verde de jitirana foi de $2,02 \%$, sendo superior ao feno de jitirana (0,97\%) citado por Araújo (1996), e inferior ao feno de feijão bravo (8,31\%) e feno de marmeleiro (3,54\%), citado por Araújo (1996).

A jitirana apresentou uma boa produção de massa verde durante $o$ período chuvoso, podendo ser utilizado na forma direta no período de produção para a alimentação de caprinos e ovinos, ou posteriormente, na forma de feno e silagens para a alimentação dos mesmos

ALBUQUERQUE, S. G de. As pastagens do semi-árido do Nordeste. Informe Agropecuário Belo Horizonte. $\mathrm{N}^{\mathrm{o}} .13$, p.40, 1988.

ARAÚJO, E. C. de; VEIRA, M. E. de. Q. Nutritive value and volontary intake of native farage of semi-arid region of Pernambuco. I - Orelha de onça (Macroptituim martii, Benth). In: INTERNATIONAL CONFERENCE ON GOATS, 4, Brasília - DF. proceedinos...

Revista Verde (Mossoró - RN - Brasil) v.1, n.1, p. 75-79 janeiro/junho de 2006

http://revista.gvaa.com.br 


\section{REVISTA VERDE DE AGROECOLOGIA E DESENVOLVIMENTO SUSTENTÁVEL GRUPO VERDE DE AGRICULTURA ALTERNATIVA (GVAA)}

Brasília: EMBRAPA - DDT, 1987, p. 1407. 1987.

ARAÚJO, E. C. de; VIEIRA, M. E de Q. Valor nutritivo e consumo voluntário de forrageiras nativas da região semi-árida de Pernambuco III - Mororó (Bauhinia Cheilantha (Bong Stend). Pesquisa Agropecuária de Pernambuco. Recife, V.7, No especial, p. 77 83, jul/dez.1990.

ARAÚJO, E. C. de; VIEIRA, M. E. Valor nutritivo e consumo voluntário de forrageiras nativas da região semi-árida de Pernambuco IV - Jitirana (Merremia aegyptia L. Urban). IN: REUNIÃO ANUAL DA SOCIEDADE BRASILEIRA DE ZOOTECNIA 33, 1996. Fortaleza. Anais... Fortaleza: SBZ, 1996. p. 260-262.

CORRÊIA, Manuel Pio. Dicionário das plantas úteis. ESAM. vol IV. 1984.

FRAGA, M. J.; BLAS, J. C.; BUXADE, C. et al. Alimentos del granado. Madrid, Espanha: Universidad Politécnica de Madrid. (Monografias de la Escuela Técnica Superior de Ingenieros Agromos, 65). 287p. 1984.

GOMES, F. P. Forragens fartas na seca. $4^{\mathrm{a}}$ ed. São Paulo: Nobel, 1977. 233p.

HARRIS, L. E. Compilação de dados analíticos e biológicos para o preparo de tabelas de composição de alimentos para uso nos trópicos da América Latina. Flórida USA: Centro de Agricultura Tropical. 5301p. 1970.
NOVELY, P.E. Aspectos do superpastoreio na produção e manejo de pastagem nativa no nordeste do Brasil. IN: SEMANA BRASILEIRA DO CAPRINO, 2, 1978. Sobral: EMBRAPA - CNPC, 1982. p. 7-19.

OLIVEIRA, M. C. de; SILVA, C. M. M. de S. Comportamento de algumas leguminosas forrageiras para pastejo direto e produção de feno na região semi-árida do Nordeste. Petrolina: EMBRAPA - CPATSA, Maio de 1988. 6p. (EMBRAPA - CPTSA. Comunicado Técnico, 24).

SALVIANO, L. M.C. e CARVALHO FILHO, O. M. de. Composições químicas e digestibilidade "in vitro" de algumas espécies forrageiras da caatinga. IN: EMPRESA BRASILEIRA DE PESQUISA AGROPECUÁRIA. Centro de Pesquisa Agropecuária do Trópico semi-árido, Petrolina - PE. Resumo dos trabalhos desenvolvidos na área de produção animal e correlatas. Petrolina, 1984. p.26.

SILVA, D. J da. Análise de Alimentos (métodos químicos e biológicos). 1 ed. Viçosa - MG, Imprensa Universitária - UFV. 165p. 1990.

VALE, L. V. Potencial forrageiro da camaratuba (Cratylia mollis, Mart) na região semi-árida norte do Ceará. IN: Congresso Brasileiro de Forrageiras e Pastagens Nativas, 1, Olinda, 1983, Resumos... Recife: IPA, 1983. m.p. 